\title{
Erratum: Unicompartmental knee arthroplasty: a review of literature
}

\section{Bernardino Saccomanni}

Published online: 1 December 2010

(C) Clinical Rheumatology 2010

\section{Erratum to: Clin Rheumatol}

\section{DOI 10.1007/s10067-009-1354-1}

This article has been retracted due to plagiarism.

The online version of the original article can be found at http://dx.doi. org/10.1007/s10067-009-1354-1.

B. Saccomanni $(\bowtie)$

Orthopaedic and Traumatologic Surgery,

University of Chieti,

via dei Vestini,

66013 Chieti, Scalo, Italy

e-mail: bernasacco@yahoo.it 